Ljiljana Marković

Univerzitet u Beogradu

Filološki fakultet удк 821.521.09-31

доИ https://doi.org/10.18485/

melissa.2016.15.1.ch1

\title{
KNJIGA KAO NOSILAC POPULARNE KULTURE
}

\begin{abstract}
Sažetak
Posle Drugog svetskog rata u japanskoj književnosti dolazi do naglog procvata književnog roda romana. Roman u japanskoj književnosti, kako modernoj, tako i u književnosti istorijski posmatrano, predstavlja prozor u kulturološke trendove japanske kulture perioda u kome je pisano. Tematika romana je usko povezana sa društvenim problemima perioda stvaralaštva, međutim, roman takođe krasi karakteristika da je pisan za običan narod, tako da je primamljiv širokom krugu čitalaca.
\end{abstract}

U japanskoj književnoj tradiciji postoje tri uzajamno povezana perioda koja obeležavaju prekretnicu u razvojnom putu japanskog romana. Period u kome dolazi do nastanka prvog romana u japanskoj književnosti (period Heian) bio je u znaku jakog civilizacijskog uticaja Kine. Tokom njega se klasični kineski jezik javlja i kao izražajno sredstvo japanske književnosti. Prvi japanski roman (nastao oko 1000. godine) pisan je fonetskim zapisom (kana), a ne kineskim ideogramima. Fonetizacija ideogramskog pisma, taj veliki civilizacijski skok ostvaren u Japanu u IX veku, oslobodila je stvaralački genije japanskih pisaca stega koje ograničenja ideogramskog pisma i klasičnog kineskog jezika nameću i po prvi put im je omogućila da, ako to žele, svoja dela stvaraju na čistom japanskom jeziku. Pojava romana Genji monogatari najbolje svedoči o tome koliko su bile značajne posledice ovog jezičkog podsticaja, kao i u razvoju romana kao žanra u japanskoj književnoj tradiciji. Ipak, još se gotovo devet vekova nije moglo pobeći od dominacije kineske civilizacije i klasičnog kineskog jezika.

$\mathrm{U}$ drugom periodu razvoja romana, posle 1600. godine (faza Tokuga$w a)$, koji je u znaku borbe za nacionalno ujedinjenje i nacionalnu afirmaciju Japana, dolazi i do uspona ovog književnog žanra. Istovremeno, i do 
afirmacije japanskog jezika kao izražajnog sredstva japanske književnosti. Raspon od dva i po veka, se može smatrati drugim zlatnim dobom procvata japanske kulture, samim tim, i slobodnijeg razvoja svih književnih oblika i rodova.

Ono što takođe krasi ovaj period je način na koji su knjige preštamapavane, po čemu je ovakva vrsta knjige i dobila naziv - drvotisna knjiga. Po ovom principu, knjige su se preštampavale tehnikom utiskivanja slogova. Uobičajeno je bilo da knjiga bude bude preštampavana dok se drveni slogovi ne istroše, a onda bi kasnije oni opet bili napravljeni, pa bi se izdanja, uz priličan broj izmena tehničke i suštinske prirode, opet obnavljala. Pri tome je svako izdanje nosilo oznaku prvog izdanja, što je otežavalo datiranje prvog otiska

U trećem periodu, dobu modernizacije Japana - počev od 1868. godine, roman se u Japanu razvija pod dominantnim uticajem zapadnoevropske književne tradicije. Međutim, i u razvoju romana, kao i na drugim poljima, u Japanu je, uprkos sveobuhvatnoj modernizaciji, očuvana i samobitna originalnost. Uočavanje stvarnog uticaja zapadnoevropske književne tradicije na japansku, u oblasti savremenog romana uopšte, a posebno romana koji govori o stvarnom životu, svakidašnjici, društvenim i ekonomskim problemima radnog čoveka - zaposlenog u velikim kompanijama, neizostavno počiva na komparativnom metodu. Neophodno je naglasiti da novelu o radnom čoveku (sarariman shōsetsu), imajući u vidu tradiciju japanskog društva, a posebno visoko shvatanje dužnosti i radnih obaveza, odlikuje posebna originalnost, kako u pogledu sadržaja, tako i u načinu koncipiranja radnje, što u znatnoj meri odudara od eventualnih zapadnoevropskih uzora. Pre bi se moglo reći da romani žanra novele o radnom čoveku ne postoje u takvom vidu i sa takvom tendencijom u zapadnoevropskoj savremenoj književnosti. Originalnosti je, možda, ličnim primerom doprineo i rodonačelnik ovog žanra Genji Keita, koji je i sam preko dvadeset šest godina bio zaposlen kao službenik velike kompanije (sarariman), a čiji je stvaralački opus imao velike zasluge za razvoj ovog književnog žanra.

Činjenica je da je japanska književna tradicija u XX veku doživela pravu renesansu, a posebno je roman napredovao kao književni rod. $U$ tom krilu trebalo bi i tražiti pojavu "novele o radnom čoveku", bez obzira 
što se istovremeno takvi književni oblici pojavljuju i u zapadnoevropskoj književnoj tradiciji. I pored uticaja zapadnoevropske književne tradicije na ovaj žanr romana u Japanu, može se slobodno tvrditi da je "novela o radnom čoveku" ipak osobena i sa društvenog i sa žanrovskog gledišta i da štiti izvesnu originalnost savremene japanske proze.

Posebno mesto u razvoju romana u modernom periodu zauzima "novela o radnom čoveku" (sarariman shōsetsu), koja je ponikavši u okrilju tzv. trivijalne književnosti, doživela u Japanu gotovo trenutni uspeh i rado prihvaćena od strane veoma široke i raznorodne čitalačke publike i, nedovoljno proučavana u savremenoj književnoj kritici.

Stekavši popularnost jer su čitani ne samo u časovima odmora, nego i na putu od kuće do radnog mesta, i u mnogim sličnim prilikama postavši, dakle, činilac kulture širokih narodnih masa. Poseban žanru trivijalne književnosti - „trivijalni roman”.

Posebna su pitanja mesta i uloge „trivijalnog romana” $u$ japanskoj $\mathrm{i}$ evropskoj književnoj tradiciji kome pripadaju i romani koji govore o problemima zaposlenih u japanskim, uglavnom, krupnim kompanijama $\underline{\text { sa- }}$ rariman shōsetsu). Posmatrajući i analizirajući ovu vrstu romana moderne japanske književsnoti, možemo videti ulogu književnosti kao predstavnika kulturološkog trendova u japanskoj kulturi, a knjigu kao posrednika između čitaoca i kulturoloških trendova. Radna i korporacijska etika, dugi radni časovi, strogo poštovanje hijerarhije, lična požrtvovanost zarad kompanije, samo su neke od karakteristika japanske kulture koji su poznati širom sveta. Život koji vodi sarariman je neretko u žiži interesovanja kao fenomen japanske kulture, pa se kroz ovakve romane čitaoci mogu upoznati sa načinom života sarimana. Kao predstavnik ovog žanra izdvaja se Genđi Keita.

Genji Keita je bio veoma plodan pisac koji je napisao desetak dužih i značajnih romana, i čitavo mnoštvo (oko 200) novela, priča i pripovedaka. U samom središtu opusa ovoga pisca stoji roman Santō Jūyaku (Zamenik direktora trećega ranga).

Genji je ovaj svoj roman počeo da objavljuje u nastavcima u novinama Sande - mainichi. Ovaj roman je izlazio u redovnim nastavcima od 12. avgusta 1952. godine do 13. marta 1953. godine. Privukao je na sebe ogromnu pažnju, kako čitalačke publike, tako i kritičara, i pomogao da Ge- 
nji zauzme izuzetno visoko mesto na lestvici popularnosti pisaca savremene japanske proze. Ovim romanom je potvrđena i Genji-jeva sposobnost iskazivanja jedne posebne vrste tananog humora koji stoji u direktnoj funkciji opisivanja veoma vešto odabranih slika iz života i radnog puta japanskog sararimana.

Najveći broj čitalaca Genjijevih dela su i sami predstavljali radne ljude koje je Genji opisivao. Genji je poput mozaika slagao umetnički transponovane detalje iz svakodnevice radnog dana japanskog službenika, dodavao mu elemente neverovatnosti, kao i sve ono što je bilo potrebno da bi se ispunile težnje koje sarariman potajno gaji u svojoj hronično umornoj duši. Prema književnom kritičaru Togaeri Hajimu, osnovni uspeh Genjijevih romana može se objasniti u potrebi masa japanskih radnih ljudi da vide sebe u svojevrsnom društvenom ogledalu - odnosno da posmatraju kako junaci - koji su im slični po obrazovanju, karakteru, ponašanju, radnim obavezama, kao i privatnom životu - uspevaju da se nose u koštac sa različitim dogodovštinama, koje se opet svakodnevno i svakom od njih događaju. Dodatni elemenat fantastike, ili uprošćavanja, Genjijev, leteći ćilim koji sararimanu omogućuje da preleti svoj trnoviti put od ulaska u kompaniju do penzionisanja, jeste Genjijev humor, optimizam i veliko samopouzdanje, stečeno na osnovu dubokog poznavanja i ličnog proživljavanja svih tih teških sararimanovih situacija koje karakterišu njegov rad u kompaniji u Japanu. U tom smislu može se komotno reći da romani Genji Keite, koje on piše o sararimanu, i koje sararimani čitaju, ispunjavaju veoma važnu duhovnu potrebu japanske čitalačke publike. U njima sararimani ne prepoznaju samo sami sebe, već i svoje prijatelje, upoznaju svoje šefove, upoznaju se sa detaljima kodeksa života u posleratnom japanskom društvu, tako da ovo štivo predstavlja svojevrsnu reinkarnaciju tzv. kodeksa samuraja (bushidoa) iz predmodernog perioda. Sarariman shōsetsu govori radnom čoveku upravo kako treba da se ponaša, kako da shvati i izdrži različite pritiske na radnom mestu, kako da se postavi prema kolegama i prema šefovima, tako da pored duhovne potrebe, ovi romani ispunjavaju i izuzetno važnu funkciju društvenog putokaza i skupa uputstava za brojne radne ljude koji su se po prvi put obreli u jednom takvom za njih veoma zbunjujućem društvenom kontekstu. Migracija radne snage iz sela u gradove bila je veoma brza u posleratnom Japanu, stopa industrijskog rasta 
od $10 \%$ godišnje zahtevala je veoma brz priliv radnika iz poljoprivrede i njihovu još bržu adaptaciju na radne uslove koje zahteva visoko industrijalizovano društvo. Duhovne potrebe ovih ljudi, pomoć u snalaženju u kompleksnom kontekstu velegrada i velike fabrike najbolje su pružali romani Genji Keite. Ništa nije moglo blagotvornije delovati na dušu polu zbunjenog i vrlo često najbukvalnije izgubljenog sararimana, koji umesto da bira između jedne od dve moguće ulice u svom malom mestu, pokušava da se orijentiše u pravoj džungli velegradova poput Tokija, Osake ili Kobea. Isto kao što "novokomponovana narodna muzika" svoju popularnost duguje istoj onoj oktavi, u kojoj se kreću i problemi, dileme i težnje naših ljudi koji su preko noći promenili životni habitus, pa im veoma utešno i nostalgično zvuče stereotipne jadikovke o izgubljenoj ljubavi, čežnji za rodnim krajem, neverstvu žene ili prijatelja, isto tako, japanskom sararimanu veoma utešno i veoma uputno deluju priče o aranžiranim brakovima, prikrivanju šefovog neverstva, potrebi slepog pokoravanja na prvi pogled neshvatljivim pravilima ponašanja u kompaniji, prihvatanju svih vrsta zabrana i naredbi slepo i kao u vojsci, ispunjavanju svih pravila kompanije bez obzira na njihovu logičnost i korisnost, odricanju od sopstvene ličnosti i identiteta i slično, koje mu pomažu da shvati kako se u srodnim situacijama treba postaviti, ili koje mu sopstvenu tešku presiju čine relativno lakšom. $U$ isto vreme u Japanu veliku popularnost uživa i srodan tip muzičkog stvaralaštva - enka, u kojima se opevaju nesrećne i zabranjene ljubavi mladih i siromašnih ljudi, koji su ne retko sararimani, na putu da prekrše neku od zabrana svoje kompanije, kao što je recimo zabrana zabavljanja sa koleginicama u istoj kompaniji.

Sarariman u svojoj karijeri, ukoliko ima veoma mnogo sreće, kao i veoma visoko obrazovanje i, ne retko društveno poreklo, može da postane i generalni direktor. Kako se ponaša čovek na takvom pijedestalu? O tome Genji veoma mnogo piše, posebno u svom najznačajnijem romanu Zamenik direktora trećeg ranga. Generalni direktor koji je u ovom romanu opisan, Kuwabara, predstavlja čoveka koji ima sve osobine tipičnog japanskog direktora iz stvarnosti, i koji svoju popularnost kod čitalačke publike duguje upravo snažnom realizmu Genji Keite. Sararimani sa oduševljenjem čitaju o Kuwabari jer je on gotovo živ čovek, samo što ne zakorači sa stranica Sande - mainichija, u njihov svakodnevni život. On je 
toliko uverljiva ličnost da ljudi osećaju da ga gotovo poznaju, on predstavlja svojevrsnu inkarnaciju njihovog "rođenog direktora". Genjijeva kritika društva i odnosa unutar kompanije, kao i samog položaja i moći kojom generalni direktor raspolaže, ogleda se u njegovom izboru naslova tog romana, pri čemu zamenik direktora trećeg ranga već samo po sebi predstavlja oštru kritiku razrađene hijerarhičnosti koja diktira životima japanskih radnih ljudi.

Još jedna velika odlika ovog romana je veoma specifičan način njegove serijalizacije. Naime, ovaj roman se sastoji od čitavog niza pojedinačnih priča, koje, mogu da predstavljaju zasebnu celinu. To je olakšavalo čitaocima da prate, iz nedelje u nedelju, tok događaja koji se opisuju, kao i razvojni put ličnosti. Opterećeni i umorni sararimani koji uglavnom jedino vreme za čitalačku aktivnost nalaze na putu ka poslu, ili na povratku sa posla (ukoliko su tada trezni) ne mogu da pamte, niti je Genji želeo da ih opterećuje potrebom da drže u rukama sve konce događaja iz prethodne epizode. Stoga se ovaj roman doživljava upravo kao majstorski povezan mozaik životnih situacija sa izrazitim heurističkim svojstvima.

Pisac je odabrao kompaniju »Nankai Sangyō", ne prvorazrednu kompaniju iz velegrada, već jednu malu kompaniju sa sedištem u provinciji. Da je ova kompanija "jedna od kompanija iz prve lige" situiranih u Tokiju ili Osaki, ne bi se mogao zamisliti Kuwabara kao njen direktor. Pisac je namerno odabrao jednu ovakvu kompaniju da bi međuljudske odnose stavio pod mikroskop sa moćnijim uvećanjem i da bi svoju analitičku oštricu približio ishodištima tipičnog sararimana, kome grad srednje veličine može da omogući daleko bolje snalaženje i kome je provincija mnogo prirodniji habitus, nego što to uspeva da mu bude velegrad. Takođe, autor nije odabrao veliku trgovinsku kompaniju, niti veliku kompozitnu korporaciju, jer je jedna ovakva proizvođačka firma kao što je "Nankai Sangyō« davala daleko više mogućnosti da se opišu produkcioni odnosi među zaposlenima koji stoje u samoj osnovi tipizacije međuljudskih odnosa na poslu. Ovakav izbor provincije olakšao je Genjiju i uvođenje elemenata humora, u čemu mu pomaže korišćenje dijalekata u direktnom govoru junaka, humorističke situacije koje sam nepravilan govor ili seoski maniri proizvode kod čitalaca - a što sve doprinosi izvanrednom osećanju svežine i životnog optimizma koji provejavaju u ovom, kao i u drugim Genji-jevim 
delima. Pisac je dobrovoljno pristao da se sam podvrgne velikim mukama, što se oseća pri kraju romana, koji je izašao u daleko većem broju nastavaka nego što je prvobitno planirano u dogovoru sa urednikom Sandemainichija, jer je uzeo na sebe da bude "žrtveni jarac" i da apsorbuje i apsolvira sve kolektivne patnje sararimana i da ih kroz svoj roman, gotovo ritualno razreši daljih muka. Tačno se uočava da su patnje pisca u direktnoj proporciji sa namernom lakoćom i svežinom kojom čitalac doživljava tako "apsolvirane situacije". Može se slobodno reći da je Genji sveštenik jedne nove religije koja sararimanu daje potrebnu utehu, pomaže da nađe sebe u burnom svetu industrijskog Japana i usmerava ga na pravi put. Ovo je samo još jedan dokaz o neizmernoj energiji kojom je Genji raspolagao i koju je morao da ponudi, onako nesebično, kako je i bilo jedino u skladu sa njegovom prirodom, svima drugima, svojim kolegama sararimanima. Sve do pojave Zamenika direktora trećeg ranga Genji je uvek govorio da će nastaviti sa svojim radom u firmi, da ga književni rad neće odvojiti od žive veze sa sararimanskom svakodnevicom. Međutim, postoje granice čak i njegovoj energiji, tako da je on konačno ipak morao da se odrekne rada u firmi, da bi se u potpunosti posvetio svojoj viziji rada na poboljšanju kvaliteta života sararimana i na ispunjenju svoje misije. I to je veoma u skladu sa japanskom tradicijom, jer su za sve životne pozive, i to počevši od onog najkasnijeg, ratničkog, postojali "putevi". Poput Miyamoto Musashija koji je napisao osnovne smernice u Putu samuraja u srednjem veku, Genji Keita u svojoj Čitanci za sararimana (Sarariman Tokuhon) daje najbolju sublimaciju svojih ideja o putu sararimana. Svaki sarariman tu može naći konkretno i eksplicitno iskazana uputstva o tome na koji način treba da se postavi u kojoj situaciji, šta dolikuje jednom sararimanu, a šta ne, kako treba gajiti svoje odnose unutar i van kompanije, sve ovo ne kroz kontekst fabule romana, već u smislu uputstava po odrednicama.

Genjija je ipak teško pogodilo to što je morao da se odrekne i svog rada u kompaniji, što je morao da preseče tu pupčanu vrpcu koja ga je držala u stalnom krvotoku same matice sararimanskog života. Njegovi radovi posle napuštanja rada u kompaniji oslikavaju ovu tugu, ovaj osećaj gubitka, njegovu duboku zabrinutost da mu se ne izmakne sama životna, osnova njegovog stvaralaštva, da mu se ne otme i nekuda ne odleprša smisao njegove misije, pa on piše radove koji predstavljaju, u suštini, la- 
ment nad sararimanskim životom. Takav je, na primer, rad Kancelarija za one koji više ne primaju platu (Mukyū Shoku taku shitsu). Ovu povezanost između Genjijevog napuštanja sararimanskog načina života i tmurne atmosfere njegovih radova prvi je uočio i donekle podvukao i objasnio Togaeri Hajime. ${ }^{172)}$

Međutim, snagom svoje umetničke ličnosti, i svoje gotovo religiozne misije spašavanja sararimana, Genji uspeva da pobedi u ovoj bici protiv samoga sebe, i uspešno nadvladava svoju melanholiju, što se ogleda u virtuoznom unošenju humorističkog obrta - tako da, recimo, penzionisanje i odlazak sa radnog mesta što je jedna od najkrupnijih tragedija sararimanovog života Genji rešava preko Kancelarije u kojoj rade bez plate, a koja omogućuje penzionisanim radnicima da i dalje svakodnevno odlaze u kompaniju i u njoj provode po čitav radni dan. Ovaj ingeniozni konstrukt sadrži toliko lepršavog humora da se teško i jedan čitalac može odupreti šarmu Genjijeve solucije, kao i oštrici njegove ironije: sararimanov život koji je pun jada i čemera, koji predstavlja produženu torturu u okviru koje sarariman ne može čak ni da odabere sa kim će se oženiti, niti šta će oblačiti, na kraju radnog veka sararimanu se čini toliko čarobnim i najboljim od svih svetova da on jednostavno nije sposoban da prihvati pomisao da život nastavi u nekom drugom miljeu. Stoga, sarariman sam dobrovoljno zahteva da mu se, makar i bez naknade, dozvoli da i dalje uživa u tom raju, tako da svoje mučilište doživljava kao habitus van čijih okvira on nije u stanju da preživi. Ne bi se oštroumnije moglo dočarati koliko parališuće na čoveka deluje atmosfera japanske kompanije od ovog snažnog opisa parališućeg efekta koju takav život ima na samu životnu sposobnost sararimana. Atmosfera japanske kompanije prvo je ubila sve živo u sararimanu, tako da on više najbukvalnije nije u stanju da opstane van njenih sterilnih uslova. Ironija situacije je da čovek kome su ubili životnost sada moli da ga pod tim zvonom ostave jer on zbilja nije u stanju da nađe svoj modus vivendi van okvira kompanije. Sarariman je izgubio ljubav prema slobodi - ona je u njemu sistematski ubijana od prvog dana početka obrazovnog procesa unutar kompanije. Sarariman je poput pripitomljene zveri koju kada kucne čas penzionisanja, dotadašnji vlasnik dobrotvorno oslobađa iz kaveza i pušta natrag u šumu. No, zver je zaboravila zakone prirode i slobodnog života, pa se sama vraća natrag u kavez i zatvara za 
sobom vrata. To je i tragedija, i ironija, i specifični humor Genji Keite, i to sve $u$ jednom dahu, otmeno i nenametljivo. Ovako majstorsko transportovanje tragičnosti sararimanovog životnog položaja predstavlja rezultat mukotrpnog rada ovog požrtvovanog pisca na trajnom pronalaženju onih pravih solucija koje će dati utisak izvanredne prirodnosti i lakoće kazivanja. Ovde se oseća i dinamična slojevitost Genjijevih radova. U prvom naletu oslobađa se čisto humoristički efekat - zvuči naučno-fantastično da jedan čovek koji se toliko dugo patio ne dočekuje penziju kao svoje oslobođenje - ne možemo da verujemo da on svaki dan prekrižuje u svom kalendaru i ne odbrojava časove do trenutka oslobođenja, pa nas suprotnost slike koju Genji prezentuje isprva iskreno zasmeje, aktivirajući reakciju na mehanizam nemogućeg. $U$ drugom talasu se, međutim, u svoj svojoj stravičnosti pojavljuje, poprimajući sve jasnije konture, ubitačna tragičnost sararimanovog položaja - odnosno njegova stvarna nemogućnost da opstane kao jedinka van visoko-shematizovanog kompanijskog života. To se graniči sa kriminalnim ispiranjem mozga, ili pak, sa oduzimanjem duše, da se za trenutak poslužimo slikom onoga što je najstrašnije, što je gotovo faustovsko. U trećem talasu, ozaruje nas ružičasta ironija ovoga velikog pisca - shvatamo sa koliko se on gorkih osmeha obraća uspešnim japanskim privrednicima i tvorcima japanskog "privrednog čuda".

Analizirajući sarariman romane možemo steći uvid ne samo u tradicionalnu kulturu naroda koji je opisan u romanu, Japanaca, već i videti na koji način se ta kultura uklopila u moderni život Japanaca. Upravo posmatrajući ovaj primer možemo zaključiti važnost knjige kao nosioca i posrednika popularne kulture, koji u isto vreme predstavlja štivo čija žiža popularnosti ne jenjava decenijama nakon pojave. 


\title{
Ljiljana Marković \\ University of Belgrade \\ Faculty of Philology
}

\section{THE BOOK AS A CARRIER OF POPULAR CULTURE}

\begin{abstract}
Summary
After the Second World War, there was a sudden flourishing of the novel as literary genre in Japanese literature. The novel in Japanese literature, both modern and historically viewed literature, represents a window into the cultural trends of the Japanese culture of the period in which it is written. The theme of novels is closely related to the social problems that are typical for the period in which they are created. However, what also characterizes the novel is the fact that it is written for ordinary people, thus it is appealing to a wide circle of readers.
\end{abstract}

